\title{
El ultraizquierdismo: enfermedad infantil de la academia
}

\author{
Ultra-leftism: Academy Childish Disease \\ O ultraesquerdismo: doença infantil da academia
}

\section{John Beverley}

UNIVERSITY OF PITTSBURGH

Profesor en el Departamento de Literaturas y Lenguajes Hispánicos de University of Pittsburgh. PhD en Literatura de la University of California at San Diego. Es autor, entre otras obras, de Subalternity and Representation: Arguments in Cultural Theory (Duke

University Press, 1999), La voz del otro: testimonio, subalternidad y verdad narrativa (Universidad Rafael Landívar, 2002) y coeditor de The Postmodernism Debate in Latin America (Duke University Press, 1995). Su último libro es Latinamericanism after 9/11 (Post-Contemporary Interventions) (Duke University Pres, 2011). Correo electrónico: brq@pitt.edu 


\section{Resumen}

En el contexto posneoliberal en el que nos encontramos, el paradigma que gobierna la constelación de los estudios culturales latinoamericanos se ha vuelto anacrónico y necesita ser modificado. El autor sostiene que las corrientes vinculadas a la exploración del concepto de poshegemonía representan, dentro del latinoamericanismo actual, una forma de ultraizquierdismo académico. En este artículo se analizan algunas de las implicaciones intelectuales y políticas de dicha posición en relación con los nuevos gobiernos de la "marea rosada".

Palabras clave: poshegemonía, ultraizquierdismo,

latinoamericanismo, estudios culturales.

Palabras descriptor: Ciencia política - América Latina, internacionales comunistas, izquierdas (Política), estudios culturales.

\section{Abstract}

In the post-neoliberal context in which we are, the paradigm that governs the constellation of the Latin American cultural studies has become outdated and it needs to be modified. The author argues that the currents of thought associated with the exploration of the concept of posthegemony represent, in today's Latin Americanism, a form of academic ultraleftism. In this article some of the intellectual and political implications of that position are discussed in relation to the new governments of the "pink tide".

Keywords: posthegemony, ultraleftism, Latin Americanism, cultural studies.

Keywords plus: Political Science - Latin America, Communist International, Left (Politics), cultural studies.

\section{Resumo}

No contexto pós-neoliberal no que encontramos-nos o paradigma que governa a constelação dos estudos culturais latino-americanos tem virado anacrônico e precisa de modificações. $\mathrm{O}$ autor sustém que as correntes vinculadas à exploração do conceito de póshegemonia representam, dentro do latino-americanismo atual, uma forma de ultraesquerdismo acadêmico. Neste artigo são analisadas algumas implicações intelectuais e políticas de tal posição em relação com os novos governos da "maré rosada".

Palavras-chave: pós-hegemonia, ultraesquerdismo, latinoamericanismo, estudos culturais. Palavras-chave descritores: Ciência Política - América Latina, Internacional Comunista, Esquerda (Politics), os estudos culturais.

RECIBIDO: 13 DE MAYO DE 2013. EVALUADO: 12 DE JUNIO DE 2013. ACEPTADO: 14 DE JUNIO DE 2013.

\section{Cómo citar este artículo:}

Beverley, John. "El ultraizquierdismo: enfermedad infantil de la academia". Cuadernos de Literatura 18.35 (2014): 18-27. 
LOS ESTUdios GULTURALES latinoamericanos, en un sentido amplio, nacieron durante los años noventa de una constelación de varias modalidades de lo que podemos llamar, para resumir, "estudios": estudios poscoloniales, subalternos, de la mujer, queer, étnicos, de los medios, etc. La aparición y la consolidación académica casi hegemónica (en las humanidades) de esta constelación fueron necesarias en dos sentidos: 1) respondía, desde la izquierda o desde una idea de una posible renovación de la izquierda , a la crisis del proyecto de la izquierda en América Latina (y mundialmente), así como de los modelos culturales asociados con ese proyecto; 2) ofrecía una alternativa al auge de los modelos neoliberales, tanto en el trabajo de la cultura como en la economía política.

Creo que todos estaríamos de acuerdo en que nos encontramos en un momento posneoliberal. En América Latina, luego de 2000; en la economía global, después de la crisis de 2008. En esta coyuntura, el paradigma que gobierna la constelación de los estudios culturales latinoamericanos se ha vuelto anacrónico y necesita ser modificado. Incluyo mi propio trabajo en esta conclusión, pero tengo en mente sobre todo las corrientes del latinoamericanismo actual que, de una forma u otra, marchan bajo el signo de la poshegemonía. Debo mencionar en particular el conocido libro de Jon Beasley-Murray, Posthegemony. Political Theory and Latin America, pero también (para dar solo unos ejemplos) la obra de Benjamín Arditi y John Holloway, versiones varias de la idea de la multitud en Hardt y Negri (v. gr. los ensayos sobre las "turbas" chavistas de Luis Duno), "el comunismo literario" de mi colega y amigo Juan Duchesne -derivado de Rancière, Deleuze, Nancy, etc.-, las corrientes deconstructivistas (Gayatri Spivak, Alberto Moreiras, Nelly Richard y la ya clausurada Revista de Crítica Cultural), los remanentes del proyecto de los estudios subalternos latinoamericanos, las posiciones en los estudios poscoloniales y queer...

A mi modo de ver, estas corrientes en conjunto representan una forma, dentro del latinoamericanismo actual, de ultraizquierdismo ${ }^{1}$. La idea de ultraizquierdismo viene de un famoso (para algunos, infame) ensayo de Lenin escrito en 1920 , "El comunismo de izquierda, una enfermedad infantil", presentado en el Segundo Congreso de la Internacional Comunista ese mismo año. El argumento del panfleto tiene que ver con lo que Lenin ve como desviaciones sectarias de los jóvenes movimientos comunistas en Inglaterra, Alemania, Holanda y Francia. Los detalles del debate no son muy interesantes hoy. Pero la situación a la que se refiere sí. La Revolución rusa ha ocurrido, el régimen soviético se ha establecido con

1 Los usos de Badiou no escapan de esta clasificación, aunque Badiou ha hecho una crítica del izquierdismo teórico. Véase Bosteels. 
grandes dificultades y distorsiones, y comienza a crear a su semejanza partidos comunistas internacionales, incluyendo los países coloniales o semicoloniales. Lenin teme que la posición ultraizquierdista, aunque inspirada precisamente en su propio modelo, el de los bolcheviques en su avance hacia el poder en Rusia, pueda impedir la marcha concreta del comunismo en otros países.

En otras palabras, Lenin argumentaba contra una posición que, supuestamente en imitación de la suya propia, rehusaba hacer pactos con partidos socialdemócratas (como el Partido Laborista en Inglaterra, por ejemplo), participar en elecciones parlamentarias o participar en acciones comunes con sindicatos establecidos. La idea básica del comunismo de izquierda era que la Revolución rusa indicaba que una revolución mundial más amplia era inminente, y que el juego político normal de elecciones, sindicatos, partidos o bloques electorales simplemente postergaba esa posibilidad. Se considera que el panfleto de Lenin forma parte del giro al estalinismo. No hay duda de que la idea de ultraizquierdismo fue usada muchas veces por el estalinismo. Sin embargo, las posiciones que critica Lenin en ese panfleto son precisamente las de Stalin durante el llamado Tercer Periodo de la Internacional Comunista, que termina con el triunfo en Europa del fascismo.

Hoy día quizá no se reconozca a muchas de las figuras contra las que Lenin polemiza, pero algunos por lo menos recordarán un libro que de cierta forma representa la articulación teórica más avanzada del comunismo de izquierda: Historia y conciencia de clase, de Georg Lukács. Este es un libro que sin duda leyó Walter Benjamin. Y Benjamin -cierto uso de Benjamin- es parte del problema del ultraizquierdismo latinoamericanista hoy. Lo que pesa sobre todo en el argumento de Lukács es la idea de la inmanencia de una conciencia colectivista, revolucionaria en la misma situación de trabajo del proletariado, una conciencia adscrita comunista. Lukács entendía por conciencia adscrita no la conciencia empírica o real del proletariado, sino la conciencia que debía tener debido a su posicionamiento en las relaciones de producción y que no era alcanzable para la burguesía por esa misma razón (es decir: la imposibilidad de pensar las relaciones sociales en su "totalidad". Esta es la base de la crítica que Lukács hace del modernismo estético).

El vicepresidente de Bolivia, Álvaro García Linera, hace eco del título y el argumento del ensayo de Lenin en una polémica relativamente reciente en la que ataca a los críticos del gobierno de Movimiento al Socialismo (MAS) desde la izquierda: el oenegismo, enfermedad infantil del derechismo. El libro está dirigido en concreto contra los firmantes de un "Documento" (llamado así), muchos de ellos antiguos simpatizantes o miembros del MAS y algunos de otras posiciones 
de izquierda; y contra el MAS, argumentando la necesidad de una "reconducción" del llamado Proceso de Cambio en Bolivia. El más conocido sea quizás el académico Raúl Prada, relacionado con el grupo Comuna (del cual también fue parte García Linera durante un tiempo). Sin entrar en detalles: desde una posición de supuesta simpatía y solidaridad con los movimientos populares, sobre todo con los movimientos de autoafirmación y autonomía indígena, se acusa al MAS -y a García Linera en particular- de desviar el proyecto socialista-indigenista en Bolivia hacia una dirección "desarrollista", mediatizada por el Estado y sintonizada con la globalización capitalista. García Linera responde que, a pesar de su adhesión formal a los movimientos sociales, los "resentidos" del "Documento", como él los llama, no entienden el trabajo práctico de la construcción del Proceso de Cambio, que tiene como horizonte la construcción de una patria socialista, y hasta cierto punto están obstaculizando y favoreciendo la oposición a este.

Me convenció el argumento de García Linera, pero como en cierto sentido fue una respuesta a una posición que pudiera haber asumido yo (desde $v$. gr. los estudios subalternos), y que de hecho han asumido muchas personas que conozco y respeto, tenía que hacerme una serie de preguntas al respecto, y eso me llevó a la hipótesis que acabo de articular: que el paradigma con el cual trabajamos en los estudios culturales latinoamericanos ha dejado de funcionar.

Como hace evidente la polémica de García Linera, lo que hoy define coyunturalmente la situación de los estudios culturales latinoamericanos es la llamada "marea rosada", es decir, el surgimiento, en los últimos diez años más o menos, de una serie de gobiernos de izquierda en Latinoamérica de carácter muy heterogéneo. No dudo de que este fenómeno lleve en sí muchas ambigüedades, contradicciones, ilusiones y peligros. Como toda empresa humana, está abierto al fracaso o a la perversión de sus ideales. ¿Se trata, como arguye García Linera, de una apertura hacia cambios más radicales, o de una nueva forma de capitalismo con una "cara más humana"? Pero no deja de ser al menos esperanzador que una mayoría de la población de América Latina viva hoy bajo gobiernos que se autodenominan, de una forma u otra, "socialistas".

Entiendo la marea rosada como un acontecimiento, en el sentido que Badiou concede a ese término: es decir, algo inesperado, impredecible, radicalmente contingente y sobredeterminado, que no obstante abre una nueva serie de posibilidades y determinaciones simplemente por haber ocurrido. La pregunta -usando otra fórmula de Badiou- es cómo ser "fiel al acontecimiento", y esto en particular desde el trabajo que hacemos en el latinoamericanismo. No se trata de insistir en que tenemos que estar de acuerdo con tal o cual medida de tal o cual gobierno. Nuestra función es una función crítica. Pero creo que sí es legítima la 


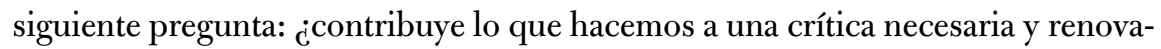
dora de las nuevas posibilidades, o más bien, en nombre de una radicalización más profunda y auténtica, no obstaculiza esa posibilidad y llega, en algunos casos, a hacer una causa común con la oposición burguesa?

En este sentido veo la cuestión del ultraizquierdismo latinoamericanista como un problema político y no solo como un debate sobre una tendencia intelectual. Dos observaciones rápidas al respecto: hasta el punto en que se puede hablar de una influencia o un impacto del trabajo académico sobre la política -volveré a este tema más tarde-, se podría decir que algunos elementos de la marea rosada se derivan en parte de la reflexión teórico-crítica del latinoamericanismo de los noventa y de comienzos de este siglo. Por ejemplo, la idea, de clara procedencia poscolonial, de patria "plurinacional". En otras palabras, sin la renovación teórica de los "estudios" (subalternos, poscoloniales, de la mujer, etc.) no hubiera sido posible la renovación política de los gobiernos de la marea rosada.

Por contraste, se habla mucho estos días de una emergente contradicción entre estos gobiernos y los movimientos sociales subalternos que los auspiciaban, especialmente los movimientos indígenas, en relación con las políticas de energía, construcción de carreteras, explotación de minerales y recursos biológicos, etc. El caso más conocido, quizás, sea uno al que se refiere García Linera en su polémica: el enfrentamiento, a veces violento, entre un grupo indígena y el MAS sobre el proyecto de construir una carretera a través del parque nacional indígena conocido como Territorio Indígena Parque Nacional Isiboro Sécure (Tipnis). Pero, como se sabe, hay contiendas similares en Ecuador, Brasil, Chile, Venezuela, etc.

Estas contiendas amenazan con poner en contradicción los dos aspectos más centrales del cambio de paradigma representado por los estudios culturales latinoamericanos en los noventa: la reivindicación poscolonial (o decolonial) de lo indígena y lo afrolatino; lo popular-subalterno como centro de la reflexión teórica y la acción política (los gobiernos de izquierda postulan la necesidad de un "desarrollo" económico para mejorar las condiciones de vida de los grupos más pobres de la población).

Para dar un ejemplo concreto de este problema: la conocida activista poscolonial Catherine Walsh opinó en una conferencia en la Universidad de Pittsburgh que las políticas de desarrollo energético del gobierno de Correa en Ecuador eran en cierto sentido más nocivas que el neoliberalismo, porque violaban los derechos de la tierra y de los grupos indígenas -establecidos en la Constitución 
ecuatoriana-, pero ahora bajo el manto de un gobierno popular, redistributivo, "plurinacional".

Me apresuro a decir que no estoy de acuerdo con la posición de Walsh: me parece, más bien, una forma de ultraizquierdismo. Pero no dudo de que nace de contradicciones reales. Y tampoco dudo del alto nivel de compromiso ético y teórico de Walsh, una persona a quien admiro mucho. Sin embargo, no creo que en estos debates la posición "decolonial" en sí o los grupos indígenas o ecológicos tengan automáticamente la razón, y el Estado no. Más bien, veo al Estado como un espacio necesario para empujar el cambio y, por lo tanto, como el lugar de una serie de contradicciones inevitables. Aun si la autonomía de territorialidades indígenas se establece como derecho inviolable, aun contra las razones de un "desarrollo" que llevaría a mejores condiciones de vida para todas las clases populares, podría haber -y de hecho hay- conflictos entre distintos grupos indígenas sobre esas territorialidades (entre otras razones, porque estas también pueden ser urbanas y "nacionales", como en el caso de los aymaras en Bolivia). Alguna instancia tiene que resolver o mediar en esos conflictos; como nacen en la sociedad civil, no pueden ser resueltos enteramente desde esta. El Estado tiene que crear un proceso de resolución, aun si ocurriese en el ámbito de las relaciones interindígenas (algunos se acordarán aquí del conflicto entre las dos comunas soviéticas en la obra El círculo de tiza caucasiano de Brecht, resuelto en cierto sentido por la representación de una obra de teatro). Para decirlo de otra manera: no creo que el socialismo o el "buen vivir" sean la venida de Cristo (o del Tahuantinsuyo), sino la elaboración de un proceso radicalmente igualitario que nunca acaba, que siempre va a producir conflictos. Pero considero que es importante la distinción entre conflictos en el seno del pueblo y conflictos entre el pueblo y el bloque de poder. El socialismo es un proceso, no una utopía.

Lenin habló de una "enfermedad infantil", caracterizada por falta de madurez, frustración, impaciencia y voluntarismo. Yo hablo de una enfermedad académica. ¿Por qué académica? Por tres razones que expongo a continuación.

En primer lugar, nuestro modelo como académicos de las humanidades (o, como los franceses solían decir, de las "ciencias humanas") es precisamente la crítica, más que la agregación hegemónica. En ese sentido una práctica permanentemente deconstructiva es algo así como la ideología espontánea de los intelectuales, para recordar un concepto de Althusser. Pero este afán crítico, que es propio de nuestra ética de trabajo, no es necesariamente compartido por otras posiciones sociales. En realidad, como Gramsci señaló, la posición del intelectual "crítico" marca precisamente una línea divisoria con los grupos subalternos actuales. Este problema se complica con la situación de clase pequeño-burguesa 
de la mayoría de los intelectuales académicos, cualquiera que sea su afiliación política concreta.

Esto nos lleva a lo que es (creo) el punto ciego más importante de las posiciones poshegemónicas en el latinoamericanismo: la confusión de lo que Althusser llamó (con mayúsculas) la Ideología en General con las ideologías particulares. Tanto el fascismo como el ecofeminismo o la doctrina del buen vivir son ideologías, pero evidentemente con consecuencias muy distintas para la vida real. Y "la ideología no tiene un afuera", insistía Althusser. Es decir, no podemos imaginar una manera de "cambiar el mundo" que no pase por la articulación ideológica.

En segundo lugar, nuestra responsabilidad ética y política es en cierto sentido autorreferencial a la academia. No admite una corrección o una responsabilidad externa. Un radicalismo extremo puede coexistir pacíficamente con una carrera académica. No lo digo para criticar -estoy, estamos, hablando aquí precisamente por eso-. Pero eso nos deja faltos de responsabilidad. Es decir, si proponemos una posición teórica y, de alguna forma, esa posición es -como en el caso del ultraizquierdismo histórico- coincidente con la derrota o el impasse de un movimiento social o político, no tenemos que sentir una responsabilidad directa por eso. Un ejemplo es la celebración del zapatismo y la defensa de su rechazo al apoyo electoral a la candidatura del Partido de la Revolución Democrática (PRD) en 2006. La defensa académica de la postura zapatista -y el aparato teórico-crítico en el que se basa (los estudios subalternos, en este contexto)- es algo también "académico"; es decir, no tiene que justificarse ante el tribunal de la historia, en este caso los más o menos sesenta mil muertos en la guerra del gobierno de Calderón contra el narcotráfico. En cierto sentido, estamos en una situación de teoría sin consecuencias.

La tercera razón es una extensión de la segunda. Es decir, la exterioridad de la crítica académica latinoamericanista en general con respecto a su objeto de estudio, América Latina. No quiero repetir aquí las viejas (y gastadas) dicotomías sobre la "posición de enunciación": local/global, periférico/metropolitano, "desde"/"sobre" América Latina, etc., algo que postularon los neoarielistas en su crítica de los estudios culturales. Tanto García Linera como Raúl Prada son intelectuales que piensan y escriben, como Nelly Richard, "desde" América Latina (y, en su caso, desde Bolivia en particular), pero eso no impide que sus posiciones sean discrepantes.

Cabe observar, más bien, que en muchas de las nociones de lo latinoamericano (o de su deconstrucción, como en Moreiras) no importa si son "sobre" o "desde" América Latina; como en la idea carpenteriana o lezamiana acerca de la naturaleza "barroca" de América Latina, hay una visión implícita de esta como 
una forma de lo sublime romántico. Hay algo de esto en la representación del "texto de la violencia": en los femicidios de Ciudad Juárez, por ejemplo, o en la fascinación actual con Bolaño (que comparto). Podríamos decir que el ultraizquierdismo de la poshegemonía tiende a una especie de sublime. Lo que pasa aquí entonces es algo parecido a lo que Benjamin llamó, en su ensayo "El autor como productor", la estetización de la política, fenómeno que él identificaba con el fascismo. En el caso del ultraizquierdismo latinoamericanista, el fenómeno tiene más bien que ver con cierta impaciencia -a veces milenaria y ciertamente pequeño-burguesa- de la inminencia del comunismo.

Termino con una anécdota, quizás como su propio protagonista, un poco demagógica: cuando era presidente, Hugo Chávez (que descanse en paz) hizo publicar una edición de un millón de copias de una versión abreviada de Don Quijote para distribuir gratis a los estudiantes de secundaria en los barrios pobres y en el campo. La edición lleva un prefacio del Premio Nobel José Saramago, en el que este cita un famoso verso de Rimbaud: "la vie est ailleurs" -la vida está más allá, o la vida está en otro lugar-. Esta podría ser la consigna del ultraizquierdismo: la posibilidad de América Latina está más allá de su situación actual y, en particular, de la posibilidad muy mediatizada, problemática, representada por los gobiernos de la marea rosada, incluyendo el de Chávez. Sin duda. Pero merece la pena resaltar que esta referencia aparezca precisamente en un texto producido masivamente para estudiantes de secundaria en Venezuela por el gobierno de Chávez.

Es siempre desde un más allá que nace la política. Pero también es una cuestión de un aquí y ahora, y de ganar elecciones.

\section{Obras citadas}

Althusser, Louis. Philosophy and the Spontaneous Philosophy of the Scientists. Londres; Nueva York: Verso, 1990.

Beasley-Murray, Jon. Posthegemony. Political Theory and Latin America. Minneapolis: University of Minnesota Press, 2010.

Benjamin, Walter. "The Author as Producer". Reflections. Nueva York: Schocken Books, 1986. 220-238.

Bosteels, Bruno. Badiou and Politics. Londres; Durham: Duke University Press, 2011. García Linera, Álvaro. El "oenegismo", enfermedad infantil del derechismo. O cómo la reconducción del Proceso de Cambio es la restauración neoliberal. La Paz: Vicepresidencia del Estado Plurinacional, Presidencia de la Asamblea Legislativa Plurinacional, s. f.

Lenin, Vladimir Ilyich. "'Left Wing' Communism: An Infantile Disorder". Collected Works. Vol. 31. Moscú: Progress Publishers, 1974. 17-118. 
Lukács, Georg. Historia y conciencia de clase. 1923. Barcelona: Grijalbo, 1968.

Saramago, José. "Prefacio". Don Quijote de la Mancha, por Miguel de

Cervantes Saavedra. Edición abreviada. 2004. Caracas: Alfaguara

y Ministerio del Poder Popular para la Cultura, 2008. 1-6.

Walsh, Catherine. Conferencia plenaria. Congreso de Estudiantes

Graduados del Department of Hispanic Languages and

Literatures. University of Pittsburgh, octubre de 2011. 